\title{
Adaptação e ficção seriada: a atualização dos conteúdos sociais em Sinhá Moça
}

\author{
Adaptation and serialized fiction teledrama: the updating of \\ social contents in Young Missy (Sinhá Moça)
}

\author{
Márcia Gomes Marques $^{[a]}$, Hellen Camara ${ }^{[b]}$
}

\begin{abstract}
[a] Doutora em Ciências Sociais pela Pontifícia Università Gregoriana, Roma, professora do Departamento de Comunicação Social e do Mestrado de Estudos e Linguagens da Universidade Federal de Mato Grosso do Sul, (UFMS), Bolsista da CAPES - Brasília / Brasil, Campo Grande, MS - Brasil, e-mail: marciagm@yahoo.com

[b] Acadêmica do curso de Comunicação Social da Universidade Federal de Mato Grosso do Sul, (UFMS), bolsista de Iniciação Científica pela FUNDECT, Campo Grande, MS - Brasil, e-mail: hellencamaran@gmail.com
\end{abstract}

\section{Resumo}

Este trabalho tem como objetivo discutir acerca de uma importante tendência da produção audiovisual na atualidade, a saber, a refeitura de obras em forma de remake ou de adaptação para a produção de "novos" produtos midiáticos. Nesse sentido, analisa-se a adaptação do romance Sinhá Moça, de Maria Dezonne Pacheco Fernandes, para o audiovisual televisivo, da qual já foram feitas duas versões em forma de ficção seriada, tratando das implicações da transposição do livro para a televisão e dos ajustes relativos ao gênero e ao suporte. Também são introduzidas questões ligadas à construção e à representação dos personagens femininos das obras, aos valores sociais a eles atribuídos, e às mudanças de comportamento e visão de mundo referentes à atualização e à contextualização conteudística. Entre os fatores relevantes para o entendimento da adaptação, disserta-se sobre a exigência de fidelidade à obra-fonte e sobre a impossibilidade de obtê-la devido aos câmbios de linguagem e de público.

Palavras-chave: Remake. Adaptação. Telenovela. Representação social. 


\begin{abstract}
This study aims at discussing an important tendency in the current production of audiovisuals for "new" media works. In this sense, the adaptation of the novel Young Missy (Sinhá Moça), by Maria Dezonne Pacheco Fernandes, for audiovisual televising, of which two versions have already been made, is discussed with focus on the implications of transposing the book for the television and all the necessary adjustments, as to genre and support. Questions connected to the construction and representation of feminine characters in the works are also introduced, along with social values attributed to them and the changes that have taken place in this sense in the process of adaptating and remaking. Among the relevant factors for understanding the adaptation, a discussion is beld on the requirement of faithfulness towards the original work and on the impossibility to achieve it, due to changes both in language and audience.
\end{abstract}

Keywords: Remake. Adaptation. Soap Operas. Social representation.

\section{Introdução}

Tal como em outras partes do mundo onde há intensa produção de ficcional, no Brasil o texto literário é comumente transportado para o audiovisual. Este processo, de adaptação é amplamente realizado independendo de suportes ou gêneros. Na televisão encontramos séries, seriados, minisséries, casos especiais e telenovelas que utilizam narrativas adaptadas da literatura. Dentro de cada um desses formatos televisivos é necessário que se tenha em conta certas limitações impostas: tempo de exibição, recursos envolvidos na produção, locações, disponibilidade de pessoal, entre outros. Somando estes fatores à escolha dos autores, que por sua vez imprimem suas marcas estilísticas e de visão de mundo no que fazem, o produto cultural é moldado para se ajustar aos padrões de cada gênero.

A telenovela é um dos gêneros mais difundidos e de maior apelo popular no país. É produzida de forma padronizada, seriada e a partir da divisão técnica do trabalho; é um produto da indústria cultural que visa ao lucro financeiro por meio da oferta de entretenimento. A sua produção tem início na década de 1950, pouco depois do advento da televisão no país, e por ter sido prontamente acolhida pelo público, tem recebido grande atenção das emissoras desde então. Ela dialoga com os espectadores, lançando tendências e comportamentos que são incorporados pela sociedade a partir da identificação do público com as tramas e os personagens ficcionais apresentados. Não raro a telenovela leva ao público elementos históricos e culturais, questionando e discutindo valores sociais.

Com a adoção da estratégia de programação por franjas de horário, as telenovelas passaram a se especializar e a direcionar seus conteúdos aos perfis de público que tipicamente se encontram em casa no momento de transmissão dos programas, atendendo aos diferentes tipos de espectadores dos domicílios brasileiros. $\mathrm{Na}$ Rede Globo, emissora que tem maior tempo e volume de produção de telenovelas no Brasil, o horário das 18 horas consagrou-se como o das novelas de época e das adaptações de obras literárias. Nesses casos, muitas vezes o desafio é ajustar a história do livro, seus temas, personagens e cenários, aos padrões exigidos tanto pelo gênero telenovela quanto pelos gostos do público desse horário, que é composto, na maior parte, por donas de casa, domésticas e adolescentes (NAGAMINI, 2004). Nos últimos anos, é frequente serem apresentados nesse horário remakes de obras já adaptadas da literatura e que foram ao ar também às $18 \mathrm{~h}$, como foi o caso de Ciranda de Pedra (2008/1981), Sinhá Moça (2006/1986) e Cabocla (2004/1979).

Um aspecto muito apontado quando se fala em adaptação literária para outros suportes é a questão da fidelidade: a tenção de ter na adaptação exatamente o que encontramos no texto original (cenários, personagens, tramas, enredo, organização cronológica dos acontecimentos). Contudo, tal desejo não leva em conta que, mesmo quando se busca a 
fidelidade, é necessário lidar com a impossibilidade de alcançá-la. Isso porque devem ser consideradas, por exemplo, as diferenças de linguagem entre a literatura e os meios audiovisuais - e, portanto, as constrições devidas à tradução intersemiótica implicada no câmbio de linguagem (MANZOLI, 2006, p. 76). Entre outros fatores, a narrativa adaptada sai de um meio puramente verbal, escrito por uma única pessoa, o seu autor, e é transferido para um meio multifacetado, cujos produtos contam com a intervenção de muitas mãos em sua feitura até chegar a um resultado considerado satisfatório para ser recebido pelo público.

$\mathrm{O}$ termo remake vem da língua inglesa e significa refazer. Nas últimas décadas, este passou a ser uma prática recorrentemente utilizada no cinema e na televisão. O remake de uma obra nada mais é que a sua refeitura: regravar uma trama ficcional valendo-se dos recursos audiovisuais existentes e dos padrões estéticos compartilhados no momento de sua realização. Embora se diferencie das adaptações que transpõem uma narrativa de um suporte a outro, o remake é também uma forma de adaptação, pois apesar de manter o suporte e o gênero, volta a produzir uma obra em outro momento histórico-cultural, com outro elenco, cenário e recursos tecnológicos. Como uma adaptação, implica certa atualização ou o ajuste da trama ao contexto social de produção.

No gênero telenovela, que tem no Brasil e em outros países da América Latina os seus grandes centros produtores, o uso do remake torna-se, cada vez mais, uma forte tendência. Um motivo para a produção de remakes é ser vantajoso para os produtores de teledramaturgia retrabalhar uma obra que já teve o seu sucesso experimentado junto ao público. Este fator proporciona aos envolvidos na produção ficcional certa "segurança" de já conhecerem seu objeto de trabalho e poderem reapresentar uma obra de grande repercussão, valendo-se da curiosidade dos antigos espectadores em rever cenas que fizeram parte de suas vivências, mas agora com novo visual, além do apelo ao novo público, caracterizado pela atualização da narrativa. Criar a partir de uma obra conhecida oferece, além disso, a possibilidade de vislumbrar os pontos de melhora e de visualizar as lacunas passíveis de serem exploradas na obra derivada. A própria Rede Globo, a maior emissora nacional produtora de telenovelas, tem lançado no mercado televisivo, todos os anos, pelo menos um remake de alguma obra que foi sucesso no passado.

No caso dessa emissora, muitas vezes o espaço de tempo entre a apresentação da primeira versão de uma telenovela e o início da exposição de seu remake é de, aproximadamente, vinte anos. Algumas das telenovelas de maior destaque de público e crítica já receberam uma nova roupagem e algumas obtiveram, novamente, grande sucesso junto aos telespectadores: Mulheres de Areia (Rede Tupi), 1973-1974/1993; Pecado Capital (Globo), 1975-1976/1998-1999; Anjo Mau (Globo), 1976/1997-1998; Selva de Pedra (Globo), 1972/1986. Recentemente foi transmitido, com grande êxito, o remake de Ti-Ti-Ti (Globo, 1985/2010), outra vez no horário das 19 horas.

A tendência de produzir remakes de telenovelas não é, no entanto, exclusiva dessa emissora. A Rede Record, que atualmente é a principal concorrente da Rede Globo entre os canais abertos de televisão no país, produziu, por exemplo, $A$ Escrava Isaura (2004-2005), uma adaptação do romance de Bernardo Guimarães, que foi sucesso de audiência da Rede Globo na década de 1970. O SBT, por sua vez, recriou obras de grande repercussão apresentadas anteriormente em outras emissoras, tal como Sangue do Meu Sangue (1995-1996), produzida pela extinta TV Excelsior (1969-1970), e Esmeralda (2004-2005), que teve uma versão venezuelana (Topasio) e também foi produzida pela mexicana Televisa, em 1997, e transmitida pelo SBT no Brasil entre 2000 e 2001.

No intervalo entre as várias versões de uma mesma obra, a sociedade está sujeita a câmbios, adquire hábitos e costumes, rompe alguns tabus e modifica valores. O próprio cenário político se transforma, e algumas destas mudanças se expressam na "nova" produção ficcional. E as telenovelas, com frequência, tocam em pontos sociais e históricos considerados de interesse, apresentando questões que são susceptíveis de chamar atenção e provocar discussão. Ao produzir um remake, a televisão invita pela segunda vez a sociedade a refletir sobre um assunto, com a diferença de fazê-lo sob a ótica do momento. Analisar um remake é, portanto, estudar as distintas afinidades telenovela versus público, obtidas por uma mesma narrativa, mas em épocas distintas e com produções diferentes. 
Nesse artigo é explorada a adaptação do romance Sinhá Moça, de Maria Dezonne Pacheco Fernandes, para a televisão na forma de telenovela. O romance foi adaptado duas vezes pela Rede Globo para o horário das $18 \mathrm{~h}$, primeiro com autoria de Benedito Ruy Barbosa, em 1986, e depois de suas filhas Edmara e Edilene Barbosa, em 2006. Apesar de serem semelhantes entre si, as adaptações diferem em vários aspectos do texto original. O interesse central, neste caso, é de refletir acerca dos ajustes feitos nas sucessivas transposições dessa obra, principalmente no que diz respeito aos personagens, às temáticas tratadas e ao desenvolvimento de enredo. No que tange aos conteúdos sociais, o foco de análise é posto na representação do feminino elaborado pelos textos em relação aos dois momentos em que a obra foi reapresentada ao público.

\section{A adaptação de Sinhá Moça}

Além do filme, produzido em 1953, nas últimas décadas foram ao ar duas adaptações teledramáticas do romance SinháMoça, ambas propondo câmbios significativos com relação à obra-fonte. As mudanças na narrativa são de iniciativa de seus recriadores. Como razão para tais modificações pode-se apontar, principalmente, que o texto original não se sustentaria no formato telenovela, devido ao escasso espessamento na composição dos personagens e à narrativa sem muitas tramas secundárias e conflitos paralelos. Na passagem para os textos televisivos foram acrescentados personagens, foi alterada a ordem cronológica dos acontecimentos, foram moldadas tramas paralelas, ou tornada as existentes mais elaboradas e ricas em detalhes.

Para entendermos melhor os movimentos feitos ao passar a história contada nesse romance para o audiovisual, é importante discutir acerca de alguns aspectos implicados ou atribuídos à transposição. Em primeiro lugar, coloca-se a questão da fidelidade da adaptação para com o texto de origem, isto é, a expectativa de que o autor da nova obra se fixe na proposta primeira e não acrescente elementos de distúrbio à obra derivada. Em outras palavras, que o novo autor não interprete, discuta, comente ou explore os aspectos que considera críticos ou especialmente chamativos na obra-fonte, nem que se ponha a acrescentar elementos que poderiam vir a enriquecer ou aprofundar os pontos de discussão que julga encontrar no texto em questão. Para Guimarães (2003, p. 95), “essa visão nega a própria natureza do texto literário, que é a possibilidade de suscitar interpretações diversas e ganhar novos sentidos com o passar do tempo e a mudança das circunstâncias".

Um segundo aspecto relevante é a identificação da relação que guardam os textos implicados nesse processo. Sanders destaca a divisão feita por Cartmell (1999, p. 24 apud SANDERS, 2008, p. 20), na qual transposição, comentário e analogia são considerados formas de adaptações de obras literárias. Estamos em contato com uma transposição quando uma obra busca trazer para o seu tempo os elementos do texto de origem. A transposição pode ser parcial ou total, quando ocorre tanto a relocação do momento histórico, dos personagens, do cenário e da linguagem da narrativa, quanto a atualização dos valores sociais. O comentário vai além da aproximação temporal para algo de maior peso cultural, explanando e questionando acerca de um cenário sociopolítico, que pode ser o do texto de partida ou o daquele que está sendo gerado. Por último, na analogia o conhecimento da obra-fonte pode enriquecer o entendimento da obra derivada, mas não é necessário para que se aprecie esse trabalho desvinculadamente. Esse é o caso dos produtos culturais que fazem menção e se aprofundam em questões propostas em outros textos, mas não se dirigem a eles diretamente, nem reafirmam esse vínculo, por meio do uso do mesmo título, por exemplo. Com relação a este modelo, pode-se afirmar que, embora a segunda versão audiovisual possa ser considerada uma transposição da primeira, o mesmo não pode ser dito com respeito à relação que essas duas versões guardam com a obra-fonte. Nesse caso se trata mais de um comentário, visto que há uma ampliação temática e um deslocamento na perspectiva de abordagem das questões introduzidas, ainda que de forma menos complexa, pelo romance.

No caso de Sinhá Moça, as obras audiovisuais expandem a discussão acerca da opressão, incluindo, ademais dos escravos, também as mulheres no debate sobre o tema, por meio das figuras, por exemplo, de Sinhá e de sua mãe, que também padecem sob o jugo do coronel Ferreira, ou de personagens como a escrava Adelaide, que combina a opressão racial 
com a de gênero sexual. Esse personagem, que não existe na obra-fonte, se enamora e contrai matrimônio com o filho de um fazendeiro, e a partir do envolvimento dos dois é tratada - em paralelo com outras linhas de enredo - a questão da miscigenação racial entre negros e brancos na época da escravidão. O exemplo de Adelaide é contraposto nas telenovelas ao de Dimas, irmão mestiço de Sinhá Moça, que nasce da violência sofrida por uma escrava da fazenda Araruna. Esse personagem, que também não existe na obra de partida, substitui o irmão caçula da protagonista do romance, só que se presta a desglosar a questão da miscigenação introduzida pelos autores das adaptações.

A ideia primeira dos defensores da fidelidade consiste em que quanto mais fiel ao texto literário o audiovisual for, melhor ele será. Subentende-se, então, que a obra literária é sempre melhor que o produto adaptado, cuja qualidade vincula-se diretamente à sua proximidade ao texto literário. Sinhá Moça é um exemplo da falibilidade desse argumento, pois a primeira adaptação para a televisão esgarça a narrativa de origem e transcende o romance, ampliando o horizonte temático e inserindo no texto outros elementos históricos e sociais, como a questão da emancipação feminina, que estava em voga quando a primeira versão televisiva foi ao ar. Para Ismail Xavier (2003), a discussão sobre fidelidade perdeu terreno para outra: a necessidade dos deslocamentos temporais, que privilegia a ideia do "diálogo" da narrativa com o seu contexto para pensar a criação das obras, adaptadas ou não. Quando acontece de uma obra ser adaptada tempos depois de sua publicação, os autores envolvidos ajustam o novo produto ao seu contexto, para que ele não falhe pela falta de entendimento ou pela capacidade de gerar identificação em seu público. Logo, é frequente que as tramas de romances escritos em outro momento, ao serem adaptadas, sejam apresentadas aos telespectadores com valores morais e sociais contemporâneos, pois:

à oposição entre o novo e o velho presente no universo ficcional corresponde também a oposição que se estabelece entre o telespectador situado no presente (e portanto identificado com o novo) e o universo ficcional situado num passado de costumes ultrapassados (GUIMARÃES, 2003, p. 105-106).
Por último, insistir na fidelidade é ignorar o fato que literatura e audiovisual constituem dois campos de produção cultural distintos, e que as obras devem ser julgadas em relação aos valores do campo no qual se inserem, e não em relação aos valores de outros campos (JOHNSON, 2003, p. 44). A primeira versão televisiva de Sinhá Moça interagiu, por exemplo, com obras de ficção seriada televisiva anteriores, no sentido de que mencionou elementos propostos por elas, renovando, revitalizando e contestando alguns deles. Um telespectador habitual facilmente vincula essa com algumas telenovelas precedentes que trataram temas como o coronelismo (Cabocla, 1979), o processo que levou a abolição da escravidão no Brasil, ou a miscigenação racial entre os descendentes de escravos e colonizadores, como é o caso de Escrava Isaura (1976-1977), com a qual a primeira versão de Sinhá Moça compartilha ainda a atriz protagonista (Lucélia Santos), ou Sinhaz̨inha Flô (1977-1978), na qual a protagonista, filha de um fazendeiro, se enamora de um jovem mestiço e pobre, filho de uma escrava.

Por esse prisma, é pertinente aplicar a noção de intertextualidade ao estudo das adaptações e remakes, como propõe Christopher Orr (1984 apud GUIMARÃES, 2003, p. 95), visto que um texto provém de vários outros textos e dialoga com eles, invalidando, então, a ideia de originalidade. Desde esta perspectiva, o romance Sinhá Moça dialoga e reapresenta elementos de tantos outros textos que vieram antes, e as adaptações, além de dialogar com a obra escrita, intertextualizam ainda com outros ficcionais que possuem temáticas afins e que são posteriores à obra-fonte.

\section{O romance}

O livro de Maria Dezonne Pacheco Fernandes, escrito em 1950 (FERNANDES, 1996), narra a estória da bela Sinhá Moça, que em épocas de campanhas a favor da abolição da escravatura, morava na Fazenda Araruna, interior de São Paulo, com seu pai, o temível Coronel Ferreira, sua mãe, dona Cândida e seu irmão caçula, o pequeno e adoentado Luís. A moça, sonhadora e abolicionista, estava sempre presente nas senzalas de seu pai buscando 
abrandar a má vida dos escravos. O comportamento e os ideais da filha são desgostos para o Coronel. No dia da festa de São Paulo, Sinhá Moça se depara com Rodolfo, filho do advogado Doutor Fontes. O moço partilha dos pensamentos de Sinhá Moça e nutre por ela sentimentos românticos, mas a menina, apesar de encantada pelo rapaz, não lhe dá muita atenção.

Nesse dia, ao voltar para a fazenda, o Coronel Ferreira destrata o escravo cocheiro Justino, que nutria sempre mais ódio pelo Coronel e esperava apenas o momento da vingança. $\mathrm{Na}$ mesma noite, ouve-se um tiro vindo da senzala. Ao procurar o feitor, o Coronel encontra-o morto e descobre que os negros haviam se rebelado em todo o vilarejo. Ele, então, corre até a delegacia e acompanhado de uma comitiva de fazendeiros, homens da vila e soldados, sai à caça dos escravos. No meio do caminho, Justino e outros negros, movidos pelo desejo de vingança, atacam o Coronel e o deixam mortalmente ferido com o golpe de um punhal, fugindo logo em seguida.

Ao saber da rebelião e preocupado com Sinhá Moça, Rodolfo vai até a fazenda. No caminho encontra Justino, que no furor do momento o derruba do cavalo e o amarra no rabo do animal, para que fosse arrastado pela mata. $\mathrm{Na}$ Fazenda Araruna, em meio a angustia, Sinhá Moça escuta o trote de um cavalo e vê pela janela que alguém estava amarrado ao animal. Ao sair para ajudar a pessoa ferida, espanta-se ao ver Rodolfo banhado em sangue. Não escondendo mais o seu amor pelo rapaz, ela o limpa e o leva para seu quarto. Enquanto Sinhá Moça cuida de Rodolfo e o faz sair do estado grave em que estava, seu pai morre no hospital, arrependendo-se de suas atitudes e reconhecendo que o escravo também tem sentimentos. Após o total restabelecimento, Rodolfo pede Sinhá Moça em casamento, que aceita.

Justino é capturado, preso e torturado, servindo, segundo os escravocratas, de exemplo aos outros negros que desejavam rebelar-se. Ao saber de sua agonizante situação, Sinhá Moça, Rodolfo, Frei José e Doutor Fontes se mobilizam pela absolvição do escravo. A heroína chega a pedir ao Juiz de Direito que perdoasse Justino como presente de casamento. O Juiz cede aos pedidos de Sinhá Moça e recorre ao Presidente da Província, presenteando-a no dia de seu casamento com o que ela desejava. Após o casamento, o casal sai em viagem, logo Sinhá Moça engravida e dá a luz a uma menina, Maria Camila. Com o auxílio de Rodolfo, sua mãe vende a Fazenda Araruna e, na companhia do filho Luis, vai morar no vilarejo perto de Sinhá Moça.

No livro, a temática principal é a da igualdade racial. Embora reclamem direitos igualitários para os escravos, o vanguardismo de Sinhá e de sua mãe para por aí. As atitudes delas confirmam a sociedade patriarcal, que restringe às mulheres os papéis de esposa, filha e mãe, sempre subjugadas aos valores masculinos e aos homens que as rodeiam. Quando da morte de seu pai, Sinhá Moça logo se casa com Rodolfo, que passa a responsabilizar-se não apenas pela esposa, mas torna-se, também, guardião e protetor de sua sogra, viúva, e de seu cunhado. Exemplo disso é que, ao retornar da lua de mel, Rodolfo viaja para a fazenda Araruna para auxiliar dona Cândida na administração. Pouco tempo depois a fazenda é vendida, pois Rodolfo não tinha planos de continuar como administrador e decide que é melhor que a sogra e o cunhado morem na cidade.

Há, nesse sentido, a ratificação de uma divisão sexual de papéis, ela encarregada da harmonia do lar e Rodolfo incumbido da gestão financeira da família. No romance reafirma-se, adicionalmente, a diferença e a oposição entre os sexos, na qual o homem "define-se basicamente por suas funções na manutenção da ordem social e na construção da cultura, enquanto a mulher, 'ser de natureza' por excelência, define-se a partir do corpo e de sua (até então inevitável) função procriadora" (KEHL, 2002, p. 12).

\section{Os conteúdos sociais: o tratamento do feminino nas adaptações}

Segundo Candido (2007), o personagem do romance torna-se visível ao público por meio da encenação de ideias, e são justamente as ideias que os mobilizam e os conduzem a partir do enredo. $\mathrm{Na}$ narrativa teledramática ocorre o mesmo: os personagens no enredo e as ideias que os animam se apresentam unidos, e juntos revelam as intenções da narrativa. As ideias fornecem aos personagens os seus atributos característicos que os habilitam a tecer o enredo e a realizar a estória. Desta forma, o personagem é sim fundamental, mas só adquire peso e espessura na narrativa, pois depende das realidades 
que o cercam para exprimir-se e atuar, no sentido de por em ato. A força e a eficácia da narrativa estão, portanto, na união desses três elementos: personagens, enredo e ideias.

A questão da tematização do romance é então fundamental, pois dará a esses três elementos, principalmente às ideias, o seu ponto de apoio na narrativa. A escolha das temáticas e das ideias pode vir do repertório de conteúdos sociais abordados preferencialmente em cada tipo de programa - nas telenovelas os conteúdos se referem, antes de tudo, à vida privada e familiar dos sujeitos. Mas a telenovela incorpora, também, temáticas debatidas em outras instâncias da sociedade, ou em outros lugares dos meios de comunicação, fomentando a discussão ao emitir um parecer, ou a sua versão, sobre o tema em contenda. Por último, a escolha da temática fica ainda a critério da produção direcionada às faixas de horários de transmissão, limitando o que pode e é adequado de ser contado de acordo com o público alvo da programação. Em se tratando de adaptação de um romance, a adequação passa tanto pelo veto parcial ou total de certos temas centrais na obra de origem, como pelo tratamento conferido a eles.

As novelas de época, do horário das 18 horas por exemplo, contam histórias de outros tempos, que muitas vezes são adaptações de obras literárias consagradas ou conhecidas pelo público por meio, inclusive, de alguma adaptação anterior feita para o teatro ou para o cinema. Mesmo quando adaptadas de um romance histórico, o resgate do passado nas telenovelas desse horário é feito, até o momento, a partir de uma abordagem branda, com tramas elaboradas para serem assistidas em família e por pessoas de várias gerações.

Como adequação dos conteúdos sociais à época, na adaptação para telenovela, a atitude da protagonistaheroína para com a sua situação é alterada. A protagonista é mostrada como uma mulher a frente de seu tempo, com ideais de autonomia e de igualdade que se somam às raciais. Isto é enfatizado desde o primeiro capítulo das adaptações, que mostra Sinhá indo da capital ao vilarejo, desacompanhada, em um trem. Na viagem ela encontra o jovem Rodolfo que, admirado em ver a moça sozinha, pede para acompanhá-la. A jovem reage ao espanto do rapaz, argumentando que ele também viajava só, e o rapaz deixa então entredito que para ele é normal viajar desacompanhado. Tal resposta deixa Sinhá Moça indignada, indicando que, segundo ela, a sua situação nada difere da dele. Ao chegar à fazenda a jovem é novamente censurada, desta vez por seu pai, que diz que tal atitude não condiz com o comportamento de uma moça direita. Ela se defende dizendo que não havia mal algum, e que apenas não queria causar incômodos. Neste sentido, a personagem nega com veemência a atribuição de anormalidade (FISCHER, 2001) atribuída ao seu comportamento. Enquanto eles indicam que ela atua de forma desviante, a heroína reafirma a sua estranheza a essa interpretação de suas atitudes.

Assumindo sua posição de classe social e desvinculando-se de sua posição de gênero sexual aceita e socialmente compartilhada na época em que se passa a história, assim que seu pai falece ela assume a administração da fazenda e recebe os imigrantes italianos que estarão trabalhando no lugar dos escravos, mostrando a eles que é ela que estará no comando da fazenda. O casal decide ter um casamento à distância, ele na capital, fazendo política e representando os produtores de café, e ela na fazenda, cuidando da produção cafeeira. Sinhá Moça e Rodolfo rompem, então, com a visão de casamento da sociedade patriarcal, na qual a mulher acompanha o marido e se submete a sua vontade. Esta outra abordagem do casamento traz a história para o contexto social em que a trama é reproposta, quase um século depois, em que há maior aceitação de que um casal more em cidades diferentes por razões profissionais.

Além das passagens mencionadas, na primeira versão e no remake da telenovela são introduzidas várias situações nas quais o desejo de liberdade feminina e de igualdade entre os sexos estão presentes. No decorrer do enredo, Sinhá Moça é expulsa de casa pelo pai por discordar energicamente de sua posição escravocrata; auxilia Rodolfo no rapto de escravos; é "raptada" por Rodolfo e casa-se com ele no quilombo. A personagem, nesse sentido, pode ser descrita como vanguardista em relação a outras mocinhas de romances que foram adaptados para o audiovisual.

Neste caso, o deslocamento de visão de mundo não se manifesta apenas em Sinhá Moça, mas também em outras personagens da novela. Dona Cândida, mãe de Sinhá Moça, que na primeira versão se mostrava submissa e temerosa do marido, raramente tendo coragem de desafiá-lo, na segunda versão é posta, em muitas cenas, em pé de igualdade com ele. Um exemplo disso é a cena em que o Barão, após expulsar a filha de casa, tem a desaprovação 
da mulher que, revoltada, vai dormir em outro aposento. O Barão não se conforma com a atitude da esposa, embriaga-se e pede a ela que volte a dormir no mesmo quarto que ele. A Baronesa continua irredutível e expulsa o marido do quarto. Nas duas versões, a Baronesa vive um breve affair com o jovem Ricardo, filho caçula do Doutor Fontes.

As mudanças de comportamento dos personagens femininos nas adaptações resultam, sobretudo, do diálogo das obras com o horizonte social dos momentos de refeitura e exibição. A primeira versão, apresentada em 1986, foi ao ar num momento em que a condição feminina descrita como "seres de natureza" estava em processo de revisão, pois devido aos métodos contraceptivos e as lutas feministas pela paridade de oportunidades e de direitos, as mulheres já podiam combinar vida familiar com atividades em outras esferas da vida social.

Em adição, a heroína da telenovela contraria a imagem apresentada na obra original. A Sinhá Moça do livro, mesmo desejando a igualdade entre as raças, só encontra sua felicidade completa no casamento e na maternidade. Já o personagem do ficcional audiovisual busca não apenas no relacionamento amoroso e na liberdade dos escravos a plenitude da sua existência, mas também em seus projetos pessoais. O seu comportamento destoa do corriqueiro nas heroínas dos romances de época, cujo perfil se funda na busca do matrimonio por amor. Se considerarmos a posição de classe do personagem em sua época, ela se situa em um lugar social no qual o casamento e a inserção no espaço doméstico é exclusivo das mulheres que confirmam a imagem do feminino construído pela sociedade burguesa (a virgem pura e a mãe de família). Personagens com o perfil da mulher livre (de prostituta à livre pensadora) são rejeitadas para ter um papel na família, núcleo fundamental da sociedade na concepção burguesa (ALVES, 2002). No entanto, ao fim da trama podemos observar que a protagonista concilia essas duas versões, enquadrando-se no perfil da mulher do fim do século XX: a mulher que, além de ser livre pensadora, é mãe, esposa e trabalhadora.

Por último, uma diferença importante entre as duas versões para o audiovisual se refere ao tratamento dado às cenas de violência contra os escravos. A segunda versão economizou nas cenas de maus tratos e até a apresentação dos escravos foi amenizada, com senzalas limpas e escravos até certo ponto bem-vestidos. A segunda versão priorizou as tramas românticas, e menos os conflitos raciais. A primeira versão discutia mais a questão da igualdade racial que a segunda, que focou mais na questão da igualdade entre os sexos.

\section{Considerações finais}

No caso das telenovelas, que têm a configuração dos personagens centrais marcada pelo esquematismo e um desenvolvimento do enredo padrão, muitos dos ajustes feitos na nova obra se justificam em função do pacto comunicativo que o gênero tem estabelecido com seus telespectadores ao longo de décadas de construção de convenções e de vínculos de colaboração. Ao se adaptar um romance histórico para a telenovela é exigido, então, que a trama seja moldada segundo os elementos característicos desse gênero. Nesse caso, se necessário, o autor insere, altera ou elimina personagens, cenas, diálogos, ambientes, acontecimentos. Pode ocorrer também, para garantir a coerência da narrativa audiovisual, a alteração do tempo e da ordem dos acontecimentos. Realizam-se, assim, as interferências necessárias para "dar ordem" à trama, ou para fazê-la inteligível no meio audiovisual e aprazível para o público assíduo às telenovelas.

Quanto aos aspectos temáticos, um primeiro elemento que deve ser particularmente ressaltado no caso das versões televisivas do romance em questão, diz respeito ao tratamento dado à condição feminina. A primeira versão para a televisão vai ao ar na década de 1980, quando as mudanças na inserção das mulheres na família e no mercado de trabalho eram debatidas em vários âmbitos sociais. Essa telenovela, acompanhada de várias outras da mesma época, coloca algumas possibilidades de reposicionamento de papéis da mulher na família, e reafirma a legitimidade de projetos de vida que associam a vida familiar com aquela laboral. Enquanto as heroínas da década de 1970 buscavam principalmente um casamento harmonioso em que pudessem realizar-se como mães e esposas, essa heroína tem projetos profissionais, e embora não tenha nenhuma formação para o mundo do trabalho, assume as rédeas da fazenda Araruna com o falecimento de seu pai. Já a esposa temerosa do romance, 
que se chama inclusive Cândida, dá lugar nas versões televisivas a mulheres que mantêm certa jovialidade, que demonstram firmeza no olhar e que despertam o interesse do jovem Ricardo, o futuro cunhado de sua filha. A questão da emancipação feminina é discutida por um conjunto de personagens, e cresce da primeira para a segunda versão, em que a protagonista perde parte da suavidade em suas colocações que tinha na versão dos anos 1980 e assume, em diversas ocasiões, o ar de quem faz discursos e "dita regras".

Uma segunda questão central, nesse caso, e que também está fortemente ancorada no momento em que a primeira versão da telenovela foi ao ar, diz respeito ao discurso sobre a miscigenação racial entre casa grande e senzala, e sobre a conformação do brasileiro como povo mestiço. À diferença do livro, os audiovisuais inserem a figura do patriarca que assedia sexualmente suas escravas, figura esta já introduzida em Escrava Isaura e que é retomada inúmeras vezes pela teledramaturgia nacional, em novelas como Xica da Silva (Manchete, 1996-1997) e Terra Nostra (Globo, 1999-2000). Além disso, há o esvaziamento político e histórico da questão da miscigenação e da escravização de outras etnias pelos povos europeus. A escravidão é mostrada como algo defendido por pessoas más e irascíveis, enquanto que aquelas boas e generosas defendem não propriamente a igualdade entre todos, porque o irmão mestiço de Sinhá não tem paridade de direitos na sucessão de seu pai, mas o compadecimento pela situação dos que sofrem e dos humildes. Do mesmo modo, os personagens maus são contrários à miscigenação e ao acolhimento de pessoas da senzala em suas famílias a partir de vínculos afetivos; já os bons demonstram completa aceitação e até perplexidade diante da rejeição de relacionamentos entre pessoas de condições econômicas, sociais e étnicas diferentes.

Sobre os ex-escravos, as adaptações deixam o futuro deles em aberto. As versões televisivas abordam de forma simplória - em épocas de grandes fluxos migratórios e de intenso debate sobre o tema - a opção de "importar" imigrantes para substituir a mão de obra local. A heroína recebe cordialmente os recém-chegados, mostrando-se ciente de seus interesses de proprietária, enquanto que os ex-escravos são finalmente livres para ir e vir, reafirmando (e naturalizando) a versão de que "foram porque quiseram".
Ainda quando tratam de temas introduzidos na obra de partida, as versões televisivas trazem as questões do romance para a sua época, subvertendo-as muitas vezes por completo. Nesse caso, a atualização da narrativa não se dá como tradução (de maneira a garantir inteligibilidade) dos aspectos propostos, mas acarreta a sua revisão propriamente dita, na medida em que mudam substancialmente as atitudes e os discursos elaborados. E, como final feliz, a protagonista já casada gera o seu primeiro filho, que é o que se espera de um desfecho de telenovela, e mantém um relacionamento marital horizontal e paritário.

\section{Referências}

ALVES, I. Imagens da mulher na literatura na modernidade e contemporaneidade. In: FERREIRA, S. L.; NASCIMENTO, E. R. do (Org.). Imagens da mulher na cultura contemporânea. Salvador: NEIM; UFBA, 2002. p. 85-98.

CANDIDO, A. A personagem do romance. In: CANDIDO, A. et al. A personagem de ficção. São Paulo: Perspectiva, 2007. p. 51-80.

FERNANDES, M. D. P. Sinhá Moça. 10. ed. São Paulo: Nacional, 1986.

FISCHER, R. B. Mídia e educação da mulher: uma discussão teórica sobre modos de enunciar o feminino na TV. Estudos Feministas, v. 9, p. 586-599, 2001.

GUIMARÃES, H. O romance do século XIX na televisão: observações sobre a adaptação de Os Maias. In: PALLEGRINI, T. etal. (Org.). Literatura, cinema, televisão. 2. ed. São Paulo: SENAC; Instituto Itaú Cultural, 2003. p. 91-114.

JOHNSON, R. Literatura e cinema, diálogo e recriação: o caso de Vidas Secas. In: PALLEGRINI, T. et al. (Org.). Literatura, cinema, televisão. 2. ed. São Paulo: SENAC; Instituto Itaú Cultural, 2003. p. 37-59.

KEHL, M. R. Sexualidade recontextualizada. In: FERREIRA, S. L.; NASCIMENTO, E. R. do (Org.). Imagens da mulher na cultura contemporânea. Salvador: NEIM; UFBA, 2002. p. 11-22.

MANZOLI, G. Cinema e letteratura. Roma: Carocci, 2006. 
NAGAMINI, E. Literatura, televisão e escola: estratégias para leitura de adaptações. São Paulo: Cortez, 2004.

SANDERS, J. Adaptation and appropriation. London: Routledge, 2008.

XAVIER, I. Do texto ao filme: a trama, a cena e a construção do olhar no cinema. In: PALLEGRINI, T. et al. (Org.). Literatura, cinema, televisão. 2. ed. São Paulo: SENAC; Instituto Itaú Cultural, 2003. p. 61-89.

Recebido: 26/05/2011

Received: 05/26/2011

Aprovado: 22/10/2011

Approved: $10 / 22 / 2011$ 